\title{
ANÁLISE DA RELAÇÃO ENTRE QUALIDADE DE VIDA, POSTURA ESTÁTICA E RISCO DE QUEDAS EM IDOSOS
}

Caroline Fagundes; Universidade Feevale; caroline@espacotao.net.br; Anna Regina Grings Barcelos; Universidade Feevale; annaggrings@gmail.com; Cléber Ribeiro Alvares da Silva; Universidade Feevale; cleberras@feevale.br; Geraldine Alves dos Santos; Universidade Feevale; geraldinesantos@feevale.br

\section{RESUMO}

Introdução: Com o avanço da idade é possível observar desvios posturais, além da redução da habilidade para controlar a postura e a marcha. Essas alterações podem limitar a mobilidade do idoso e interferir nas oscilações corporais dificultando a manutenção do equilíbrio estático e da marcha segura, aumentando a chance desses indivíduos caírem. A queda no idoso pode resultar em incapacidade funcional afetando negativamente a sua qualidade de vida e de seus familiares e/ou cuidadores, além de estar associada ao aumento do risco para mortalidade, morbidade, incapacidade física e cognitiva, inatividade e depressão. Objetivo: Analisar a relação da qualidade de vida com a postura estática e o risco de quedas em pessoas idosas. Método: Participaram dessa pesquisa 55 sujeitos, de ambos os sexos, com idade entre 60 e 79 anos, praticantes de hidroginástica. Para a coleta de dados os seguintes instrumentos foram utilizados: EUROHISQOL, Postural Assessment Software (SAPO) e Escala de Equilíbrio de Berg. Resultados: Observou-se correlação significativa entre qualidade de vida e postura estática, ou seja, quanto maior o alinhamento postural, maior o índice de qualidade de vida. Vale destacar o quesito satisfação com a capacidade de desempenhar as atividades do cotidiano com o ângulo do tornozelo direito ( $r h o=0,382$ ). Constatou-se não haver relação entre a qualidade de vida e o risco de quedas. Conclusão: A partir dos achados do presente estudo é possível elaborar medidas de prevenção aos desalinhamentos posturais estáticos, e assim, reduzir o impacto negativo que essas modificações provocam na vida dos indivíduos com 60 anos ou mais.

Palavras-chave: Idosos; Postura estática; Qualidade de vida; Quedas. 